Seção Temática: Balanço do Fundeb

Volume 10 - $2020 \mid$ n. 27

\title{
Fundeb: uma avaliação da evolução do número de matrículas e escolas na educação básica
}

\author{
Nicholas Davies \\ Universidade Federal Fluminense (UFF), Niterói/RJ - Brasil
}

\author{
Alzira Batalha Alcântara \\ Universidade Estácio de Sá (UNESA), Rio de Janeiro/RJ - Brasil \\ Universidade do Estado do Rio de Janeiro (UERJ), Rio de Janeiro/RJ - Brasil
}

\section{Resumo}

O artigo, por meio de análise de censos educacionais, objetiva oferecer um quadro da evolução do número de matrículas, escolas estaduais e municipais (de 2007 a 2019) e privadas (de 2006 a 2019) na educação básica no Brasil e de sua participação em relação ao total em cada estado. Constata-se redução nacional de matrículas estaduais (-6.620.267, ou $-30,2 \%)$, municipais $(-1.503 .390$, ou $-6,1 \%)$, queda do número de escolas estaduais e municipais e da participação estadual e pequeno aumento da presença municipal. Já nas redes privadas cresceu o número de matrículas $(+1.788 .582$, ou $+24,3 \%)$, escolas e sua participação. Aponta-se a insuficiência de explicações (queda da taxa de natalidade, programas de correção de fluxo escolar) dadas para essa redução e sugere-se ser muito mais provável que ações ou omissões governamentais, ao diminuírem o número de matrículas e escolas públicas, estimularam a expansão privada. Diante dessa evolução, conclui-se que o Fundeb não manteve nem desenvolveu o número de matrículas e escolas da educação básica pública.

Palavras-chave: Censos educacionais. Educação básica. Matrícula escolar. Fundeb.

Fundeb: an assessment of the evolution of the number of enrolments

\section{and schools in Brazilian basic education}

\begin{abstract}
The article is intended, on the basis of educational census, to provide a picture of the evolution of state and municipal enrolments and schools between 2007 and 2019 and private enrolments and schools between 2006 and 2019 in basic education (all schooling prior to higher education) in Brazil, and their share in every state. The study found a national reduction in the number of state $(-6,620,267$, or $-30.2 \%)$ and municipal $(-1,503,390$, or $-6.1 \%)$ enrolments, a decline in the state share and a small municipal growth. On the other hand, the number of private enrolments $(+1,788,582$, or $+24.3 \%)$ and schools has increased, as well as the private share. It points out the insufficiency of explanations for this reduction (decline in birth rate) and suggests that it is much more likely that government actions or omissions have stimulated the private growth by reducing the number of public enrolments and schools. In view of this evolution, the article concludes that Fundeb has not maintained nor developed the number of public basic education enrolments and schools.
\end{abstract}

Keywords: Educational census. Basic education. School enrolments. Fundeb. 


\section{Introdução}

Este artigo objetiva oferecer um quadro da evolução do número de matrículas e escolas estaduais e municipais, de 2007 a 2019, e privadas, de 2006 a 2019, na educação básica no Brasil e a participação das matrículas nesses anos, e assim verificar os possíveis efeitos do Fundo de Manutenção e Desenvolvimento da Educação Básica e de Valorização dos Profissionais da Educação (Fundeb), apresentado pelos seus defensores como um fundo que iria corrigir males do Fundo de Manutenção e Desenvolvimento do Ensino Fundamental e de Valorização do Magistério (Fundef). O ano de 2007 foi escolhido como referência inicial para as matrículas e escolas estaduais e municipais porque foi o primeiro ano de vigência do Fundeb. Entretanto, no caso das matrículas privadas, foram utilizados os dados de 2006, porque 3 mil escolas privadas teriam deixado de fornecer os dados em 2007, resultando na ausência estimada de cerca de 600 mil matrículas, segundo a Sinopse Estatística da Educação Básica de 2008 (BRASIL, 2009, p. 5).

No caso das matrículas estaduais e municipais, não foram usados os dados de 2006 porque eles teriam registrado dupla contagem de alunos, de acordo com a Introdução da Sinopse Estatística da Educação Básica de 2007 (BRASIL, 2008b, p. 6-7), segundo a qual "[...] mudanças no procedimento de coleta de informações do Censo Escolar, que, ao contar com informações dos indivíduos e ter data de referência modificada, [reduziram] de maneira drástica a dupla contagem de alunos".

Algumas observações importantes sobre os dados apresentados aqui. Uma é que a educação básica nos Censos é mais abrangente do que no Fundeb, pois este, ao contrário dos Censos, não contempla matrículas semipresenciais e educação profissional (cursos concomitantes e subsequentes) não integrada à educação de jovens e adultos e ao ensino médio.

Outra é que a versão do Censo de 2007 que consultamos em 21/11/2018 e não mais disponível no site do Inep registrava as matrículas de EJA presencial e semipresencial, porém não a versão deste censo republicada em outubro de 2019 pelo governo empossado em janeiro de 2019, que não informa se as matrículas de EJA são presenciais ou semipresenciais, cujo total parece englobar presenciais e semipresenciais. Esse governo republicou em outubro de 2019 todos os censos de 2007 em diante, com significativa redução do número de tabelas publicadas em censos disponíveis antes dessa republicação e, portanto, detalhamento, aparentemente atribuindo a si a autoria do censo, pois insere na capa dessa nova versão o seu lema, "Pátria Amada". Um outro problema dessa nova versão é não apresentar justificativa para uma nova edição, além de conter dados que conflitam com a versão anterior, que consultamos. Por exemplo, a versão do censo de 2007 , que consultamos em novembro de 2018 , registrava 32.122.273 matrículas no ensino fundamental, confirmado pelo resumo técnico do censo de 2010 disponível no site do Inep em 25 de maio de 2020, número diferente do publicado na versão republicada pelo governo em outubro de 2019: 32.346.623.

Outra observação é que em 2007 e 2008 o Fundeb só considerou 1/3 e 2/3, respectivamente, das matrículas da educação infantil, ensino médio e educação de jovens e adultos, só computando a totalidade dessas matrículas a partir de 2009. Já as matrículas do ensino fundamental regular e especial pública foram consideradas em sua totalidade a partir de 2007. 
Este texto não pretende avaliar muitos outros aspectos do Fundeb, por limitação de espaço e também porque já foram tratados em alguma medida por outros textos, como os de Carvalho (2014), Bueno e Pergher (2017), Davies (2008), Martins (2008; 2011), Peres et al. (2015), Pinto (2007; 2015), Pinto, Ribeiro e Sonobe (2018), Sales e França (2018).

Inicialmente, cabe lembrar que o Fundeb foi criado pela Emenda Constitucional No. 53, em 2006, e regulamentado pela Lei No. 11.494, em 2007. Ao contrário do que muitos supunham e supõem, traz pouco dinheiro novo para o sistema educacional como um todo, pois consiste apenas numa repartição, entre o governo estadual e as prefeituras de cada estado, de $20 \%$ de vários impostos desses governos com base nos critérios de (a) número de matrículas municipais na educação infantil e no ensino fundamental (EF) e matrículas estaduais no EF e no ensino médio (EM), e (b) pesos diferentes atribuídos aos diferentes níveis, modalidades e estabelecimentos de ensino da educação básica. Em função dessa lógica, os ganhos (quando a receita é superior à contribuição) de alguns governos resultam em perdas (receita inferior à contribuição) iguais para outros governos dentro do mesmo estado. Em outras palavras, o Fundeb redistribui, entre o governo estadual e as prefeituras, uma parte dos impostos já vinculados constitucionalmente à manutenção e desenvolvimento do ensino (MDE), não havendo, pois, dinheiro novo para a maioria dos sistemas educacionais. O único dinheiro novo é a complementação federal para os Fundebs estaduais, cujo valor per capita (matrícula) não alcance o valor mínimo nacional, fixado anualmente pelo governo federal sem qualquer critério de custo-aluno-qualidade. Ainda assim, a complementação é pequena em termos nacionais, representando apenas $10 \%$ da receita nacional. Ou seja, o Fundeb é financiado basicamente por estados e municípios (90\%), o que mostra a fragilidade do suposto pacto federativo.

São várias as justificativas para o estudo. Uma é que são poucos os levantamentos sobre a evolução do número de matrículas, conforme constatado em consulta a edições de 2010 a abril de 2020 de muitos periódicos acadêmicos educacionais classificados pela Capes como Qualis A1 e A2 e periódicos que, mesmo não sendo A1 e A2, publicam muito sobre o financiamento da educação, como o Fineduca e o Jornal de Políticas Educacionais ${ }^{1}$. Outra razão consiste nas expectativas de que o Fundeb iria manter e desenvolver a educação básica pública e valorizar os profissionais da educação e porque estão em tramitação no Congresso Nacional propostas de emenda constitucional que pretendem tornar o Fundeb permanente, o que pressupõe, por parte dos autores e apoiadores dessas propostas, que o Fundeb tenha sido plena ou grandemente positivo para a educação básica. Este texto não pretende entrar no mérito do Fundeb permanente, mas esclarecer alguns dos equívocos e expectativas sobre o atual Fundeb.

Além da introdução e das conclusões, o texto divide-se em três seções. A seção 1 mostra e comenta a evolução do número de matrículas estaduais e municipais (2007-2019) e

1 Os seguintes periódicos foram consultados: Cadernos Cedes, Cadernos de Pesquisa (Fundação Carlos Chagas), Educação (UFSM), Educação (PUCRS), Educação e Contemporaneidade (Univ. Est. Bahia), Educação e Cultura Contemporânea (Univ. Estácio Sá), Educação e Pesquisa (USP), Educação e Realidade (UFRGS), Educação Temática Digital (Unicamp), Ensaio (Cesgranrio), Estudos em Avaliação Educacional (Fundação Carlos Chagas), Educação e Sociedade, Educar em Revista (UFPR), Educação em Questão (UFRN), Educação em Revista (UFMG), Perspectiva (UFSC), Práxis Educativa (Univ. Est. Ponta Grossa), Próposições (Unicamp), Revista Brasileira de Educação (Anped), Revista Brasileira de Estudos Pedagógicos (Inep), Revista Brasileira de História da Educação, Revista Brasileira de Política e Administração da Educação (Anpae), Revista de Educação Pública (UFMT). 
privadas (2006-2019) na educação básica, a classificação percentual de tal evolução, questionando o peso dado em explicações para a queda das matrículas públicas, como o declínio da taxa de natalidade. Em seguida, a seção 2 registra a evolução do número de escolas no mesmo período. A seção 3, por sua vez, apresenta a participação das matrículas estaduais, municipais e privadas em cada estado, mostrando que de modo geral a participação estadual diminuiu, a municipal cresceu pouco e a privada aumentou no período em cada unidade da federação.

\section{Número de matrículas estaduais e municipais caiu, porém, número de matrículas privadas cresceu}

A Tabela 1 mostra a evolução do número de matrículas estaduais e municipais (20072019) e privadas (2006-2019) na educação básica no Brasil, nas regiões e nas Unidades da Federação. O número de estaduais no Brasil diminuiu 6.620.267 $(-30,2 \%)$, em todas as regiões e estados, desde o máximo de -2.016.697 (-39,3\%), no Nordeste, até o mínimo de 355.795 (-18,6\%), no Centro-Oeste, com percentuais intermediários no Norte (-457.724, ou $21 \%)$, Sul (1.015.132-, ou $-29,7 \%$ ) e Sudeste (-2.775.218, ou $-29,9 \%)$. Convém frisar que a evolução percentual deve ser vista também juntamente com a evolução numérica. Por exemplo, os percentuais estaduais de queda foram semelhantes no Rio de Janeiro $(-45,2 \%)$ e Paraíba (-44,7\%), porém, no primeiro (-609.053), a redução numérica foi muito maior do que no segundo (-206.796). Vale lembrar que, como não há município no Distrito Federal, o espaço municipal do DF aparece em branco em todas as tabelas e as matrículas públicas do DF são lançadas como estaduais, sendo, por isso, proporcionalmente muito maiores do que as demais redes estaduais.

O número de matrículas municipais também caiu no Brasil $(-1.503 .390$, ou $-6,1 \%)$, porém, ao contrário das estaduais, houve um declínio em apenas duas regiões: no Nordeste, com uma redução bem mais significativa $(-1.642 .258$, ou $-16,7 \%)$ e, secundariamente, no Sudeste (-231.380, ou -2,9\%). Já o aumento das municipais ocorreu em três regiões: Norte $(+24.555$, ou $+0,9 \%)$, Sul $(+211.224$, ou $+8 \%)$, e Centro-Oeste $(+134.469$, ou $+10,7 \%)$. O Nordeste foi a região que mais perdeu matrículas públicas, tanto estaduais $(-39,3 \%)$ quanto municipais $(-16,7 \%)$, uma redução de 3.658 .955 matrículas.

O setor privado, por sua vez, cresceu no Brasil $(+1.788 .582$, ou $+24,3 \%)$ e em todas as regiões e na vasta maioria dos estados, desde o mínimo de $+17,4 \%$ (+100.491 matrículas), no Centro-Oeste, até o máximo de $+30 \%(+106.188)$, no Norte, com percentuais intermediários no Nordeste $(+21,3 \%$, ou +440.980$)$, Sul $(+25,4 \%$, ou +236.387$)$ e Sudeste $(+26,5 \%$, ou +905.036$)$. Vale lembrar que estudos de Pinto (2015) e Pinto et al. (2018) já registravam queda de matrículas na educação básica a partir de 2010 e o "colossal fechamento de escolas rurais".

Portanto, equivocou-se a Confederação Nacional dos Trabalhadores em Educação (CNTE) ao alegar que "o Fundeb já provou ser um instrumento extraordinário para aumentar o número de matrículas nas escolas", no documento Cinco razões para apoiar o Fundeb permanente (CNTE, 2020). Outros tendem a cometer o mesmo equívoco. 
Tabela 1 - Número e evolução numérica e percentual de matrículas estaduais e municipais em 2007 e 2019 e privadas em 2006 e 2019 na educação básica

\begin{tabular}{|c|c|c|c|c|c|c|c|c|c|c|c|c|}
\hline & \multicolumn{4}{|c|}{ Estadual } & \multicolumn{4}{|c|}{ Municipal } & \multicolumn{4}{|c|}{ Privada } \\
\hline & 2007 & 2019 & Ev. num. & Ev.\% & 2007 & 2019 & Ev. num. & Ev.\% & 2006 & 2019 & Ev.num. & Ev. \% \\
\hline BRASIL & 21.927.300 & 15.307 .033 & -6.620 .267 & $-30,2$ & 24.531 .011 & 23.027 .621 & -1.503 .390 & $-6,1$ & 7.346.203 & 9.134 .785 & 1.788 .582 & 24,3 \\
\hline NORTE & 2.177.846 & 1.720 .421 & -457.425 & $-21,0$ & 2.671 .573 & 2.696.128 & 24.555 & 0,9 & 354.135 & 460.323 & 106.188 & 30,0 \\
\hline Rondônia & 257.414 & 195.085 & -62.329 & $-24,2$ & 184.733 & 168.215 & -16.518 & $-8,9$ & 40.811 & 43.503 & 2.692 & 6,6 \\
\hline Acre & 152.799 & 149.833 & -2.966 & $-1,9$ & 83.762 & 99.398 & 15.636 & 18,7 & 12.068 & 12.486 & 418 & 3,5 \\
\hline Amazonas & 501.008 & 459.735 & -41.273 & $-8,2$ & 597.841 & 606.694 & 8.853 & 1,5 & 83.473 & 87.921 & 4.448 & 5,3 \\
\hline Roraima & 94.304 & 76.073 & -18.231 & $-19,3$ & 31.936 & 71.534 & 39.598 & 124,0 & 6.665 & 15.778 & 9.113 & 136,7 \\
\hline Pará & 790.342 & 568.534 & -221.808 & $-28,1$ & 1.557 .011 & 1.476 .215 & -80.796 & $-5,2$ & 158.436 & 235.365 & 76.929 & 48,6 \\
\hline Amapá & 151.115 & 118.791 & -32.324 & $-21,4$ & 52.535 & 77.410 & 24.875 & 47,3 & 21.842 & 21.310 & -532 & $-2,4$ \\
\hline Tocantins & 230.864 & 152.370 & -78.494 & $-34,0$ & 163.755 & 196.662 & 32.907 & 20,1 & 30.840 & 43.960 & 13.120 & 42,5 \\
\hline NORDESTE & 5.130 .081 & 3.113 .384 & -2.016 .697 & $-39,3$ & 9.861 .791 & 8.219 .533 & -1.642 .258 & $-16,7$ & 2.064 .454 & 2.504 .934 & 440.480 & 21,3 \\
\hline Maranhão & 547.587 & 322.961 & -224.626 & $-41,0$ & 1.561 .918 & 1.414 .160 & -147.758 & $-9,5$ & 218.330 & 237.326 & 18.996 & 8,7 \\
\hline Piauí & 335.931 & 236.000 & -99.931 & $-29,7$ & 617.695 & 534.736 & -82.959 & $-13,4$ & 123.711 & 112.476 & -11.235 & $-9,1$ \\
\hline Ceará & 645.381 & 417.009 & -228.372 & $-35,4$ & 1.670 .593 & 1.314 .605 & -355.988 & $-21,3$ & 392.497 & 418.273 & 25.776 & 6,6 \\
\hline Rio Grande do Norte & 359.440 & 216.206 & -143.234 & $-39,8$ & 468.490 & 413.309 & -55.181 & $-11,8$ & 146.724 & 171.324 & 24.600 & 16,8 \\
\hline Paraíba & 451.037 & 249.241 & -201.796 & $-44,7$ & 595.860 & 514.037 & -81.823 & $-13,7$ & 140.837 & 195.188 & 54.351 & 38,6 \\
\hline Pemambuco & 923.105 & 575.604 & -347.501 & $-37,6$ & 1.319.296 & 1.113 .913 & -205.383 & $-15,6$ & 450.885 & 524.547 & 73.662 & 16,3 \\
\hline Alagoas & 275.750 & 174.932 & -100.818 & $-36,6$ & 637.620 & 529.058 & -108.562 & $-17,0$ & 91.720 & 150.526 & 58.806 & 64,1 \\
\hline Sergipe & 234.911 & 150.087 & -84.824 & $-36,1$ & 316.419 & 268.231 & -48.188 & $-15,2$ & 71.909 & 120.406 & 48.497 & 67,4 \\
\hline Bahia & 1.356 .939 & 771.344 & -585.595 & $-43,2$ & 2.673 .900 & 2.117 .484 & -556.416 & $-20,8$ & 427.841 & 574.868 & 147.027 & 34,4 \\
\hline SUDESTE & 9.289 .648 & 6.514 .430 & -2.775 .218 & $-29,9$ & 8.113 .860 & 7.882 .480 & -231.380 & $-2,9$ & 3.418 .747 & 4.323 .783 & 905.036 & 26,5 \\
\hline Minas Gerais & 2.551 .433 & 1.870 .861 & -680.572 & $-26,7$ & 1.928 .047 & 1.748 .301 & -179.746 & $-9,3$ & 666.520 & 700.911 & 34.391 & 5,2 \\
\hline Espírito Santo & 312.061 & 247.721 & -64.340 & $-20,6$ & 490.148 & 513.069 & 22.921 & 4,7 & 130.376 & 107.358 & -23.018 & $-17,7$ \\
\hline Rio de Janeiro & 1.348 .636 & 739.583 & -609.053 & $-45,2$ & 1.826 .840 & 1.681 .988 & -144.852 & $-7,9$ & 856.835 & 1.111.732 & 254.897 & 29,7 \\
\hline São Paulo & 5.077 .518 & 3.656 .265 & -1.421 .253 & $-28,0$ & 3.868 .825 & 3.939 .122 & 70.297 & 1,8 & 1.765 .016 & 2.403 .782 & 638.766 & 36,2 \\
\hline SUL & 3.414 .306 & 2.399 .174 & -1.015 .132 & $-29,7$ & 2.624 .905 & 2.836 .129 & 211.224 & 8,0 & 932.271 & 1.168 .658 & 236.387 & 25,4 \\
\hline Paraná & 1.353 .670 & 1.034 .030 & -319.640 & $-23,6$ & 1.047 .053 & 1.058 .376 & 11.323 & 1,1 & 365.869 & 455.405 & 89.536 & 24,5 \\
\hline Santa Catarina & 738.642 & 526.368 & -212.274 & $-28,7$ & 640.965 & 790.410 & 149.445 & 23,3 & 214.322 & 273.024 & 58.702 & 27,4 \\
\hline Rio Grande do Sul & 1.321 .994 & 838.776 & -483.218 & $-36,6$ & 936.887 & 987.343 & 50.456 & 5,4 & 352.080 & 440.229 & 88.149 & 25,0 \\
\hline CENTRO-OESTE & 1.915 .419 & 1.559 .624 & -355.795 & $-18,6$ & 1.258 .882 & 1.393 .351 & 134.469 & 10,7 & 576.596 & 677.087 & 100.491 & 17,4 \\
\hline Mato Grosso do Sul & 304.864 & 229.751 & -75.113 & $-24,6$ & 305.929 & 353.037 & 47.108 & 15,4 & 83.866 & 91.860 & 7.994 & 9,5 \\
\hline Mato Grosso & 439.271 & 387.397 & -51.874 & $-11,8$ & 353.778 & 372.051 & 18.273 & 5,2 & 76.000 & 110.979 & 34.979 & 46,0 \\
\hline Goiás & 669.908 & 489.327 & -180.581 & $-27,0$ & 599.175 & 668.263 & 69.088 & 11,5 & 250.625 & 278.532 & 27.907 & 11,1 \\
\hline Distrito Federal & 501.376 & 453.149 & -48.227 & $-9,6$ & & & & & 166.105 & 195.716 & 29.611 & 17,8 \\
\hline
\end{tabular}

Fontes: Censos Escolares de 2006, 2007 e 2019 (BRASIL. MEC. INEP, 2007; 2008a; 2020) e cálculos efetuados pelos autores. 
A Tabela 2 registra a classificação percentual crescente (da menor para a maior) da evolução do número de matrículas estaduais. Em todas as Unidades da Federação, o número caiu, desde o máximo de -45,2\% (-609.053 matrículas), no Rio de Janeiro, até o mínimo de 1,9\% (-2.966), no Acre. Chama a atenção o fato de que, além do Rio de Janeiro, Rio Grande do Sul e Tocantins, as perdas mais expressivas foram em todos os estados do Nordeste.

Tabela 2 - Classificação percentual crescente da evolução do número de matrículas estaduais na educação básica de 2007 a 2019

\begin{tabular}{|c|c|c|c|c|c|}
\hline & & 2007 & 2019 & Ev. num. & Ev. \% \\
\hline 1. & Rio de Janeiro & 1.348 .636 & 739.583 & -609.053 & $-45,2$ \\
\hline 2. & Paraíba & 451.037 & 249.241 & -201.796 & $-44,7$ \\
\hline 3. & Bahia & 1.356 .939 & 771.344 & -585.595 & $-43,2$ \\
\hline 4. & Maranhão & 547.587 & 322.961 & -224.626 & $-41,0$ \\
\hline 5. & Rio Grande do Norte & 359.440 & 216.206 & -143.234 & $-39,8$ \\
\hline 6. & Pernambuco & 923.105 & 575.604 & -347.501 & $-37,6$ \\
\hline 7. & Alagoas & 275.750 & 174.932 & -100.818 & $-36,6$ \\
\hline 8. & Rio Grande do Sul & 1.321 .994 & 838.776 & -483.218 & $-36,6$ \\
\hline 9. & Sergipe & 234.911 & 150.087 & -84.824 & $-36,1$ \\
\hline 10. & Ceará & 645.381 & 417.009 & -228.372 & $-35,4$ \\
\hline 11. & Tocantins & 230.864 & 152.370 & -78.494 & $-34,0$ \\
\hline 12. & Piauí & 335.931 & 236.000 & -99.931 & $-29,7$ \\
\hline 13. & Santa Catarina & 738.642 & 526.368 & -212.274 & $-28,7$ \\
\hline 14. & Pará & 790.342 & 568.534 & -221.808 & $-28,1$ \\
\hline 15. & São Paulo & 5.077 .518 & 3.656 .265 & -1.421 .253 & $-28,0$ \\
\hline 16. & Goiás & 669.908 & 489.327 & -180.581 & $-27,0$ \\
\hline 17. & Minas Gerais & 2.551 .433 & 1.870 .861 & -680.572 & $-26,7$ \\
\hline 18. & Mato Grosso do Sul & 304.864 & 229.751 & -75.113 & $-24,6$ \\
\hline 19. & Rondônia & 257.414 & 195.085 & -62.329 & $-24,2$ \\
\hline 20. & Paraná & 1.353 .670 & 1.034 .030 & -319.640 & $-23,6$ \\
\hline 21. & Amapá & 151.115 & 118.791 & -32.324 & $-21,4$ \\
\hline 22. & Espírito Santo & 312.061 & 247.721 & -64.340 & $-20,6$ \\
\hline 23. & Roraima & 94.304 & 76.073 & -18.231 & $-19,3$ \\
\hline 24. & Mato Grosso & 439.271 & 387.397 & -51.874 & $-11,8$ \\
\hline 25. & Distrito Federal & 501.376 & 453.149 & -48.227 & $-9,6$ \\
\hline 26. & Amazonas & 501.008 & 459.735 & -41.273 & $-8,2$ \\
\hline 27. & Acre & 152.799 & 149.833 & -2.966 & $-1,9$ \\
\hline
\end{tabular}

Fontes: Censos Escolares de 2007 e 2019 (BRASIL. MEC. INEP, 2008a; 2020) e cálculos efetuados pelos autores.

A Tabela 3 informa a classificação percentual crescente (da menor para a maior) da evolução do número de matrículas municipais, que diminuiu em 13 estados e cresceu em 13. A redução variou enormemente, desde o máximo de $-21,3 \%$ (-355.988), no Ceará, até o mínimo de $-5,2 \%$ (-80.796), no Pará. O crescimento oscilou desde o mínimo de $+1,1 \%$ (+11.323), no Paraná, até o máximo de $+124 \%(+39.598)$, em Roraima. Embora os valores percentuais sejam menores se comparados à Tabela 2, o Nordeste lidera as maiores perdas, o que surpreende porque a imensa maioria das prefeituras da região teve receitas adicionais expressivas em virtude da complementação federal e das perdas dos governos estaduais do Nordeste com o Fundeb, perdas essas provocadas pelo fato de eles terem participação 
pequena e decrescente nas matrículas na educação básica pública. Vale lembrar que todos os governos estaduais perderam com o Fundeb, mesmo aqueles que receberam complementação federal.

Tabela 3 - Classificação percentual crescente da evolução do número de matrículas municipais na educação básica de 2007 a 2019

\begin{tabular}{llllll}
\hline & & 2007 & 2019 & Ev. num. & Ev. $\%$ \\
1. & Ceará & 1.670 .593 & 1.314 .605 & -355.988 & $-21,3$ \\
2. & Bahia & 2.673 .900 & 2.117 .484 & -556.416 & $-20,8$ \\
3. & Alagoas & 637.620 & 529.058 & -108.562 & $-17,0$ \\
4. & Pernambuco & 1.319 .296 & 1.113 .913 & -205.383 & $-15,6$ \\
5. & Sergipe & 316.419 & 268.231 & -48.188 & $-15,2$ \\
6. & Paraíba & 595.860 & 514.037 & -81.823 & $-13,7$ \\
7. & Piauí & 617.695 & 534.736 & -82.959 & $-13,4$ \\
8. & Rio Grande do Norte & 468.490 & 413.309 & -55.181 & $-11,8$ \\
9. & Maranhão & 1.561 .918 & 1.414 .160 & -147.758 & $-9,5$ \\
10. & Minas Gerais & 1.928 .047 & 1.748 .301 & -179.746 & $-9,3$ \\
11. & Rondônia & 184.733 & 168.215 & -16.518 & $-8,9$ \\
12. & Rio de Janeiro & 1.826 .840 & 1.681 .988 & -144.852 & $-7,9$ \\
13. & Pará & 1.557 .011 & 1.476 .215 & -80.796 & $-5,2$ \\
14. & Paraná & 1.047 .053 & 1.058 .376 & 11.323 & 1,1 \\
15. & Amazonas & 597.841 & 606.694 & 8.853 & 1,5 \\
16. & São Paulo & 3.868 .825 & 3.939 .122 & 70.297 & 1,8 \\
17. & Espírito Santo & 490.148 & 513.069 & 22.921 & 4,7 \\
18. & Mato Grosso & 353.778 & 372.051 & 18.273 & 5,2 \\
19. & Rio Grande do Sul & 936.887 & 987.343 & 50.456 & 5,4 \\
20. & Goiás & 599.175 & 668.263 & 69.088 & 11,5 \\
21. & Mato Grosso do Sul & 305.929 & 353.037 & 47.108 & 15,4 \\
22. & Acre & 83.762 & 99.398 & 15.636 & 18,7 \\
23. & Tocantins & 163.755 & 196.662 & 32.907 & 20,1 \\
24. & Santa Catarina & 640.965 & 790.410 & 149.445 & 23,3 \\
25. & Amapá & 52.535 & 77.410 & 24.875 & 47,3 \\
26. & Roraima & 31.936 & 71.534 & 39.598 & 124,0 \\
\hline
\end{tabular}

Fontes: Censos Escolares de 2007 e 2019 (BRASIL. MEC. INEP, 2008a; 2020) e cálculos efetuados pelos autores

A Tabela 4 mostra a classificação decrescente (da maior para a menor) da evolução do número de matrículas privadas, que aumentou em 24 Estados, desde o máximo de $+136,7 \%$ (+9.113), em Roraima, até o mínimo de $+3,54 \%(+418)$, no Acre. Apenas em 3 estados o número caiu: Amapá $(-2,4 \%$ ou -532$)$, Piauí $(-9,1 \%$, ou -11.235$)$, Espírito Santo $(-17,7 \%$, ou 23.018). 
Tabela 4 - Classificação percentual decrescente da evolução do número de matrículas privadas na educação básica de 2006 a 2019

\begin{tabular}{|c|c|c|c|c|c|}
\hline & & 2006 & 2019 & Ev. num. & Ev. \% \\
\hline 1. & Roraima & 6.665 & 15.778 & 9.113 & 136,7 \\
\hline 2. & Sergipe & 71.909 & 120.406 & 48.497 & 67,4 \\
\hline 3. & Alagoas & 91.720 & 150.526 & 58.806 & 64,1 \\
\hline 4. & Pará & 158.436 & 235.365 & 76.929 & 48,6 \\
\hline 5. & Mato Grosso & 76.000 & 110.979 & 34.979 & 46,0 \\
\hline 6. & Tocantins & 30.840 & 43.960 & 13.120 & 42,5 \\
\hline 7. & Paraíba & 140.837 & 195.188 & 54.351 & 38,6 \\
\hline 8. & São Paulo & 1.765 .016 & 2.403 .782 & 638.766 & 36,2 \\
\hline 9. & Bahia & 427.841 & 574.868 & 147.027 & 34,4 \\
\hline 10. & Rio de Janeiro & 856.835 & 1.111 .732 & 254.897 & 29,7 \\
\hline 11. & Santa Catarina & 214.322 & 273.024 & 58.702 & 27,4 \\
\hline 12. & Rio Grande do Sul & 352.080 & 440.229 & 88.149 & 25,0 \\
\hline 13. & Paraná & 365.869 & 455.405 & 89.536 & 24,5 \\
\hline 14. & Distrito Federal & 166.105 & 195.716 & 29.611 & 17,8 \\
\hline 15. & Rio Grande do Norte & 146.724 & 171.324 & 24.600 & 16,8 \\
\hline 16. & Pernambuco & 450.885 & 524.547 & 73.662 & 16,3 \\
\hline 17. & Goiás & 250.625 & 278.532 & 27.907 & 11,1 \\
\hline 18. & Mato Grosso do Sul & 83.866 & 91.860 & 7.994 & 9,5 \\
\hline 19. & Maranhão & 218.330 & 237.326 & 18.996 & 8,7 \\
\hline 20. & Rondônia & 40.811 & 43.503 & 2.692 & 6,6 \\
\hline 21. & Ceará & 392.497 & 418.273 & 25.776 & 6,6 \\
\hline 22. & Amazonas & 83.473 & 87.921 & 4.448 & 5,3 \\
\hline 23. & Minas Gerais & 666.520 & 700.911 & 34.391 & 5,2 \\
\hline 24. & Acre & 12.068 & 12.486 & 418 & 3,5 \\
\hline 25. & Amapá & 21.842 & 21.310 & -532 & $-2,4$ \\
\hline 26. & Piauí & 123.711 & 112.476 & -11.235 & $-9,1$ \\
\hline 27. & Espírito Santo & 130.376 & 107.358 & -23.018 & $-17,7$ \\
\hline
\end{tabular}

Fontes: Censos Escolares de 2006 e 2019 (BRASIL. MEC. INEP, 2007; 2020) e cálculos efetuados pelos autores.

Os censos e resumos técnicos do INEP e outros textos dizem que a evolução das matrículas se explica pela transição demográfica (queda da taxa de natalidade) e pela melhoria do fluxo escolar (por meio de classes de aceleração de aprendizagem, por exemplo). Sem negar a importância desses fatores, acreditamos que ações ou omissões de governos estaduais e municipais tiveram muita importância em tal evolução negativa, por várias razões. Uma é que, na ausência de grandes guerras ou epidemias, a redução da taxa de natalidade é gradual, não abrupta, e, portanto, para este fator ter muita importância a queda do número de matrículas teria de ser também gradual, porém o que se observa são diminuições grandes (sobretudo estaduais), inclusive de um ano para outro, como mostram os Censos de todos os anos de 2007 a 2019. Outra é que, se o argumento da transição fosse tão importante, a queda das matrículas estaduais e municipais seria mais ou menos semelhante em todas as regiões e redes ou sem enormes diferenças entre elas, o que não aconteceu. Se tal argumento tivesse fundamento, as matrículas privadas também teriam diminuído, o que não ocorreu na imensa maioria dos estados. Assim, cabe indagar se o encolhimento das matrículas estaduais na 
educação básica não teria contribuído para o crescimento das matrículas privadas na maior parte dos estados.

\section{Evolução numérica e percentual de escolas estaduais e municipais (2007-2019) e privadas (2006-2019) na educação básica no Brasil}

A Tabela 5 mostra a evolução do número de escolas no Brasil, nas regiões e nas Unidades da Federação. O número de escolas estaduais no Brasil diminuiu em $2.954(-8,9 \%)$, com grandes variações entre 4 regiões, desde o máximo de -1.570 escolas $(-19,4 \%)$, no Nordeste, até o mínimo de -113 escolas $(-2,8 \%)$, no Norte, com percentuais intermediários no Sul (-6,7\%, ou -421 unidades) e Sudeste $(-7,5 \%$, ou -898 estabelecimentos). A única região com crescimento foi o Centro-Oeste $(+1,7 \%$, ou +48 escolas).

Também o número de escolas municipais caiu nacionalmente $(-18,2 \%$, ou -24.136$)$ e nas cinco regiões do País. A redução se concentrou no Nordeste, única região com diminuição em todos os estados (-30,7\%, com 19.785 escolas a menos), seguido pelo Norte $(-16,1 \%$, ou $-3.149)$, Sul $(-6,4 \%$, ou -932$)$, Sudeste $(-0,8 \%$, ou -240$)$ e Centro-Oeste $(-0,6 \%$, ou -30$)$. O Nordeste foi a região que mais perdeu escolas públicas, tanto estaduais quanto municipais.

Já o setor privado cresceu no Brasil $(+16,6 \%$, ou +5.897$)$ e em todas as regiões, desde o mínimo de $+9,5 \%(+947)$, no Nordeste, até o máximo de $+34,4 \%(+457)$, no Norte, com percentuais intermediários no Centro-Oeste $(+12,3 \%$, ou +280$)$, Sul $(+19,1 \%$, ou +954$)$ e Sudeste $(+19,2 \%$, ou +3.259$)$. O Sul foi a única região com crescimento em todos os estados.

As Tabelas 6, 7 e 8, mais adiante, mostram, respectivamente, a classificação percentual da evolução estadual, municipal e privada. Vale ressaltar que a evolução percentual deve ser vista também juntamente com a evolução numérica. Por exemplo, os percentuais da queda do número de escolas estaduais do Maranhão (-13,2\%) e Rio Grande do Sul $(-12,2 \%)$ são parecidos, porém a diminuição numérica no primeiro $(-162)$ foi bem menor do que no segundo $(-344)$.

Tabela 5 - Número e evolução numérica e percentual de estabelecimentos estaduais e municipais em 2007 e 2019 e privados em 2006 e 2019 na educação básica

\begin{tabular}{|c|c|c|c|c|c|c|c|c|c|c|c|c|}
\hline \multirow[b]{2}{*}{ Região/Unidade da Federação } & \multicolumn{4}{|c|}{ Estadual } & \multicolumn{4}{|c|}{ Municipal } & \multicolumn{4}{|c|}{ Privada } \\
\hline & 2007 & 2019. & Ev. num. & Ev. \% & 2007 & 2019 & Ev. num. & Ev. \% & 2006 & 2019. & Ev.num. & Ev. \% \\
\hline BRASIL & 33.114 & 30.160 & -2.954 & $-8,9$ & 132.454 & 108.318 & -24.136 & $-18,2$ & 35.537 & 41.434 & 5.897 & 16,6 \\
\hline NORTE & 4.049 & 3.936 & -113 & $-2,8$ & 19.528 & 16.379 & -3.149 & $-16,1$ & 1.329 & 1.786 & 457 & 34,4 \\
\hline Rondônia & 392 & 410 & 18 & 4,6 & 1.200 & 664 & -536 & $-44,7$ & 204 & 158 & -46 & $-22,5$ \\
\hline Acre & 675 & 619 & -56 & $-8,3$ & 1.002 & 898 & -104 & $-10,4$ & 41 & 42 & 1 & 2,4 \\
\hline Amazonas & 563 & 747 & 184 & 32,7 & 4.594 & 4.248 & -346 & $-7,5$ & 283 & 307 & 24 & 8,5 \\
\hline Roraima & 391 & 375 & -16 & $-4,1$ & 312 & 418 & 106 & 34,0 & 13 & 49 & 36 & 276,9 \\
\hline Pará & 1.054 & 900 & -154 & $-14,6$ & 10.763 & 8.858 & -1.905 & $-17,7$ & 561 & 976 & 415 & 74,0 \\
\hline Amapá & 428 & 389 & -39 & $-9,1$ & 298 & 366 & 68 & 22,8 & 72 & 80 & 8 & 11,1 \\
\hline Tocantins & 546 & 496 & -50 & $-9,2$ & 1.359 & 927 & -432 & $-31,8$ & 155 & 174 & 19 & 12,3 \\
\hline NORDESTE & 8.095 & 6.525 & -1.570 & $-19,4$ & 64.442 & 44.657 & -19.785 & $-30,7$ & 9.987 & 10.934 & 947 & 9,5 \\
\hline Maranhão & 1.229 & 1.067 & -162 & $-13,2$ & 11.727 & 9.583 & -2.144 & $-18,3$ & 925 & 1.067 & 142 & 15,4 \\
\hline Piauí & 799 & 656 & -143 & $-17,9$ & 6.120 & 3.318 & -2.802 & $-45,8$ & 559 & 462 & -97 & $-17,4$ \\
\hline Ceará & 681 & 726 & 45 & 6,6 & 8.653 & 5.156 & -3.497 & $-40,4$ & 1.770 & 1.603 & -167 & $-9,4$ \\
\hline Rio Grande do Norte & 790 & 586 & -204 & $-25,8$ & 2.876 & 2.199 & -677 & $-23,5$ & 592 & 674 & 82 & 13,9 \\
\hline Paraíba & 1.069 & 654 & -415 & $-38,8$ & 4.830 & 3.256 & -1.574 & $-32,6$ & 765 & 932 & 167 & 21,8 \\
\hline Pemambuco & 1.107 & 1.057 & -50 & $-4,5$ & 7.476 & 5.073 & -2.403 & $-32,1$ & 2.403 & 2.346 & -57 & $-2,4$ \\
\hline Alagoas & 340 & 309 & -31 & $-9,1$ & 2.744 & 2.066 & -678 & $-24,7$ & 334 & 593 & 259 & 77,5 \\
\hline
\end{tabular}




\begin{tabular}{|c|c|c|c|c|c|c|c|c|c|c|c|c|}
\hline Sergipe & 399 & 336 & -63 & $-15,8$ & 1.816 & 1.330 & -486 & $-26,8$ & 275 & 422 & 147 & 53,5 \\
\hline Bahia & 1.681 & 1.134 & -547 & $-32,5$ & 18.200 & 12.676 & -5.524 & $-30,4$ & 2.364 & 2.835 & 471 & 19,9 \\
\hline SUDESTE & 11.906 & 11.008 & -898 & $-7,5$ & 28.893 & 28.653 & -240 & $-0,8$ & 16.957 & 20.216 & 3.259 & 19,2 \\
\hline Minas Gerais & 3.912 & 3.600 & -312 & $-8,0$ & 9.972 & 8.392 & -1.580 & $-15,8$ & 3.992 & 3.987 & -5 & $-0,1$ \\
\hline Espirito Santo & 605 & 452 & -153 & $-25,3$ & 2.698 & 2.257 & -441 & $-16,3$ & 481 & 352 & -129 & $-26,8$ \\
\hline Rio de Janeiro & 1.654 & 1.275 & -379 & $-22,9$ & 4.876 & 5.242 & 366 & 7,5 & 3.579 & 4.749 & 1.170 & 32,7 \\
\hline São Paulo & 5.735 & 5.681 & -54 & $-0,9$ & 11.347 & 12.762 & 1.415 & 12,5 & 8.905 & 11.128 & 2.223 & 25,0 \\
\hline SUL & 6.316 & 5.895 & -421 & $-6,7$ & 14.674 & 13.742 & -932 & $-6,4$ & 4.984 & 5.938 & 954 & 19,1 \\
\hline Paraná & 2.084 & 2.142 & 58 & 2,8 & 5.083 & 5.158 & 75 & 1,5 & 2.064 & 2.180 & 116 & 5,6 \\
\hline Santa Catarina & 1.417 & 1.282 & -135 & $-9,5$ & 4.218 & 3.831 & -387 & $-9,2$ & 1.032 & 1.086 & 54 & 5,2 \\
\hline Rio Grande do Sul & 2.815 & 2.471 & -344 & $-12,2$ & 5.373 & 4.753 & -620 & $-11,5$ & 1.888 & 2.672 & 784 & 41,5 \\
\hline CENTRO-OESTE & 2.748 & 2.796 & 48 & 1,7 & 4.917 & 4.887 & -30 & $-0,6$ & 2.280 & 2.560 & 280 & 12,3 \\
\hline Mato Grosso do Sul & 367 & 361 & -6 & $-1,6$ & 783 & 946 & 163 & 20,8 & 446 & 419 & -27 & $-6,1$ \\
\hline Mato Grosso & 661 & 772 & 111 & 16,8 & 1.765 & 1.487 & -278 & $-15,8$ & 333 & 430 & 97 & 29,1 \\
\hline Goiás & 1.105 & 1.014 & -91 & $-8,2$ & 2.369 & 2.454 & 85 & 3,6 & 1.059 & 1.134 & 75 & 7,1 \\
\hline Distrito Federal & 615 & 649 & 34 & 5,5 & & & & & 442 & 577 & 135 & 30,5 \\
\hline
\end{tabular}

Fontes: Censos Escolares de 2006, 2007 e 2019 (BRASIL. MEC. INEP, 2007; 2008a; 2020) e cálculos efetuados pelos autores.

A Tabela 6 registra a classificação percentual crescente (da menor para a maior) da evolução do número de escolas estaduais. Em 20 estados, a queda variou desde o máximo de $-38,8 \%$ (-415 unidades), na Paraíba, até o mínimo de -0,9\% (-54 escolas), em São Paulo. O número aumentou em 7 , desde o mínimo de $+2,8 \%(+58)$, no Paraná, até o máximo de $+32,7 \%$ (+184), no Amazonas. Chama a atenção o fato de várias das maiores perdas percentuais se concentrarem no Nordeste, Espírito Santo e Rio de Janeiro.

Tabela 6 - Classificação percentual crescente da evolução do número de estabelecimentos estaduais na educação básica de 2007 a 2019

\begin{tabular}{|c|c|c|c|c|c|}
\hline & & 2007 & 2019 & Ev. numérica & Ev. percentual \\
\hline 1. & Paraíba & 1.069 & 654 & -415 & $-38,8$ \\
\hline 2. & Bahia & 1.681 & 1.134 & -547 & $-32,5$ \\
\hline 3. & Rio Grande do Norte & 790 & 586 & -204 & $-25,8$ \\
\hline 4. & Espírito Santo & 605 & 452 & -153 & $-25,3$ \\
\hline 5. & Rio de Janeiro & 1.654 & 1.275 & -379 & $-22,9$ \\
\hline 6. & Piauí & 799 & 656 & -143 & $-17,9$ \\
\hline 7. & Sergipe & 399 & 336 & -63 & $-15,8$ \\
\hline 8. & Pará & 1.054 & 900 & -154 & $-14,6$ \\
\hline 9. & Maranhão & 1.229 & 1.067 & -162 & $-13,2$ \\
\hline 10. & Rio Grande do Sul & 2.815 & 2.471 & -344 & $-12,2$ \\
\hline 11. & Santa Catarina & 1.417 & 1.282 & -135 & $-9,5$ \\
\hline 12. & Tocantins & 546 & 496 & -50 & $-9,2$ \\
\hline 13. & Amapá & 428 & 389 & -39 & $-9,1$ \\
\hline 14. & Alagoas & 340 & 309 & -31 & $-9,1$ \\
\hline 15. & Acre & 675 & 619 & -56 & $-8,3$ \\
\hline 16. & Goiás & 1.105 & 1.014 & -91 & $-8,2$ \\
\hline 17. & Minas Gerais & 3.912 & 3.600 & -312 & $-8,0$ \\
\hline 18. & Pernambuco & 1.107 & 1.057 & -50 & $-4,5$ \\
\hline 19. & Roraima & 391 & 375 & -16 & $-4,1$ \\
\hline 20. & Mato Grosso do Sul & 367 & 361 & -6 & $-1,6$ \\
\hline 21. & São Paulo & 5.735 & 5.681 & -54 & $-0,9$ \\
\hline 22. & Paraná & 2.084 & 2.142 & 58 & 2,8 \\
\hline
\end{tabular}




\begin{tabular}{llllll}
\hline 23. & Rondônia & 392 & 410 & 18 & 4,6 \\
24. & Distrito Federal & 615 & 649 & 34 & 5,5 \\
25. & Ceará & 681 & 726 & 45 & 6,6 \\
26. & Mato Grosso & 661 & 772 & 111 & 16,8 \\
27. & Amazonas & 563 & 747 & 184 & 32,7 \\
\hline
\end{tabular}

Fontes: Censos escolares de 2007 e 2019 (BRASIL. MEC. INEP, 2008a; 2020) e cálculos efetuados pelos autores.

A Tabela 7 informa a classificação crescente (da menor para a maior) da evolução do número de escolas municipais, que diminuiu em 19 estados e cresceu em 7 . A redução variou enormemente, desde o máximo de $-45,8 \%$ (-2802), no Piauí, até o mínimo de $-7,5 \%$ (-346), no Amazonas. O crescimento oscilou desde o mínimo de $+1,5 \%(+75)$, no Paraná, até o máximo de $+34 \%(+106)$, em Roraima. Surpreende que as maiores perdas municipais se concentraram no Nordeste, porque a maioria das prefeituras da região tiveram ganhos expressivos com a complementação federal e com as perdas dos governos estaduais do Nordeste com o Fundeb.

Tabela 7 - Classificação crescente da evolução do número de estabelecimentos municipais na educação básica de 2007 a 2019

\begin{tabular}{|c|c|c|c|c|c|}
\hline & & 2007 & 2019 & Ev. numérica & Ev. percentual \\
\hline 1. & Piauí & 6.120 & 3.318 & -2.802 & $-45,8$ \\
\hline 2. & Rondônia & 1.200 & 664 & -536 & $-44,7$ \\
\hline 3. & Ceará & 8.653 & 5.156 & -3.497 & $-40,4$ \\
\hline 4. & Paraíba & 4.830 & 3.256 & -1.574 & $-32,6$ \\
\hline 5. & Pernambuco & 7.476 & 5.073 & -2.403 & $-32,1$ \\
\hline 6. & Tocantins & 1.359 & 927 & -432 & $-31,8$ \\
\hline 7. & Bahia & 18.200 & 12.676 & -5.524 & $-30,4$ \\
\hline 8. & Sergipe & 1.816 & 1.330 & -486 & $-26,8$ \\
\hline 9. & Alagoas & 2.744 & 2.066 & -678 & $-24,7$ \\
\hline 10. & Rio Grande do Norte & 2.876 & 2.199 & -677 & $-23,5$ \\
\hline 11. & Maranhão & 11.727 & 9.583 & -2.144 & $-18,3$ \\
\hline 12. & Pará & 10.763 & 8.858 & -1.905 & $-17,7$ \\
\hline 13. & Espírito Santo & 2.698 & 2.257 & -441 & $-16,3$ \\
\hline 14. & Minas Gerais & 9.972 & 8.392 & -1.580 & $-15,8$ \\
\hline 15. & Mato Grosso & 1.765 & 1.487 & -278 & $-15,8$ \\
\hline 16. & Rio Grande do Sul & 5.373 & 4.753 & -620 & $-11,5$ \\
\hline 17. & Acre & 1.002 & 898 & -104 & $-10,4$ \\
\hline 18. & Santa Catarina & 4.218 & 3.831 & -387 & $-9,2$ \\
\hline 19. & Amazonas & 4.594 & 4.248 & -346 & $-7,5$ \\
\hline 20. & Paraná & 5.083 & 5.158 & 75 & 1,5 \\
\hline 21. & Goiás & 2.369 & 2.454 & 85 & 3,6 \\
\hline & Rio de Janeiro & 4.876 & 5.242 & 366 & 7,5 \\
\hline & São Paulo & 11.347 & 12.762 & 1.415 & 12,5 \\
\hline & Mato Grosso do Sul & 783 & 946 & 163 & 20,8 \\
\hline & Amapá & 298 & 366 & 68 & 22,8 \\
\hline 26. & Roraima & 312 & 418 & 106 & 34,0 \\
\hline
\end{tabular}

Fontes: Censos escolares de 2007 e 2019 (BRASIL. MEC. INEP, 2008a; 2020) e cálculos efetuados pelos autores. 
A Tabela 8 informa a classificação decrescente (da maior para a menor) da evolução do número de escolas privadas, que aumentou em 20 estados, desde o máximo de $+276,9 \%$ (+36), em Roraima, até o mínimo de $+2,4 \%(+1)$, no Acre. Em 7 estados, a redução oscilou do mínimo de $-0,1 \%$ (-5), em Minas Gerais, até o máximo de -26,8\% (-129), no Espírito Santo.

Tabela 8 - Classificação decrescente da evolução do número de estabelecimentos privados na educação básica de 2006 a 2019

\begin{tabular}{|c|c|c|c|c|c|}
\hline & & 2006 & 2019 & Ev. numérica & Ev. percentual \\
\hline 1. & Roraima & 13 & 49 & 36 & 276,9 \\
\hline 2. & Alagoas & 334 & 593 & 259 & 77,5 \\
\hline 3. & Pará & 561 & 976 & 415 & 74,0 \\
\hline 4. & Sergipe & 275 & 422 & 147 & 53,5 \\
\hline 5. & Rio Grande do Sul & 1.888 & 2.672 & 784 & 41,5 \\
\hline 6. & Rio de Janeiro & 3.579 & 4.749 & 1.170 & 32,7 \\
\hline 7. & Distrito Federal & 442 & 577 & 135 & 30,5 \\
\hline 8. & Mato Grosso & 333 & 430 & 97 & 29,1 \\
\hline 9. & São Paulo & 8.905 & 11.128 & 2.223 & 25,0 \\
\hline 10. & Paraíba & 765 & 932 & 167 & 21,8 \\
\hline 11. & Bahia & 2.364 & 2.835 & 471 & 19,9 \\
\hline 12. & Maranhão & 925 & 1.067 & 142 & 15,4 \\
\hline 13. & Rio Grande do Norte & 592 & 674 & 82 & 13,9 \\
\hline 14. & Tocantins & 155 & 174 & 19 & 12,3 \\
\hline 15. & Amapá & 72 & 80 & 8 & 11,1 \\
\hline 16. & Amazonas & 283 & 307 & 24 & 8,5 \\
\hline 17. & Goiás & 1.059 & 1.134 & 75 & 7,1 \\
\hline & Paraná & 2.064 & 2.180 & 116 & 5,6 \\
\hline & Santa Catarina & 1.032 & 1.086 & 54 & 5,2 \\
\hline & Acre & 41 & 42 & 1 & 2,4 \\
\hline & Minas Gerais & 3.992 & 3.987 & -5 & $-0,1$ \\
\hline 22. & Pernambuco & 2.403 & 2.346 & -57 & $-2,4$ \\
\hline & Mato Grosso do Sul & 446 & 419 & -27 & $-6,1$ \\
\hline & Ceará & 1.770 & 1.603 & -167 & $-9,4$ \\
\hline & Piauí & 559 & 462 & -97 & $-17,4$ \\
\hline 26. & Rondônia & 204 & 158 & -46 & $-22,5$ \\
\hline 27. & Espírito Santo & 481 & 352 & -129 & $-26,8$ \\
\hline
\end{tabular}

Fontes: Censos escolares de 2006 e 2019 (BRASIL. MEC. INEP, 2007; 2020) e cálculos efetuados pelos autores.

\section{A participação estadual e municipal (2007-2019) e privada (2006- 2019) na educação básica no Brasil, nas regiões e nos Estados}

A Tabela 9 registra essa participação com base nos números de matrículas informados na Tabela 1. Como os percentuais foram arredondados para cima ou para baixo, a totalização estadual, municipal e privada não é necessariamente 100\%. No Brasil, o percentual estadual caiu de $40,8 \%$, em 2007, para 32,2\%, em 2019, com queda em todas as regiões. O Norte diminuiu de $41,9 \%$ para $35,3 \%$, o Nordeste, de $30,1 \%$, para $22,5 \%$, o Sudeste, de $44,6 \%$ para $34,8 \%$, o Sul, de $49 \%$ para $37,5 \%$ e, o Centro-Oeste, de $51,1 \%$, para $43 \%$. Nos estados, em 2007 a participação estadual variou do mínimo de 23,5\%, no Maranhão, até o máximo de 
71\%, em Roraima. Em 2019, essa participação diminuiu em todos os estados, sendo de $16,4 \%$ o mínimo, no Maranhão, e de $57,3 \%$ o máximo, no Acre. Não se consideram as matrículas do DF porque ele funciona como estado e município e sua inclusão distorceria o cálculo percentual.

A participação municipal no Brasil, mesmo com diminuição das suas matrículas, cresceu pouco, de $45,6 \%$ para $48,5 \%$, com ampliação em todas as regiões: Norte (de $51,3 \%$ para $55,3 \%$ ), Nordeste (de $57,8 \%$ para $59,4 \%$ ), Sudeste (de $39 \%$ para $42,1 \%$ ), Sul (de $37,7 \%$ para 44,3\%), Centro-Oeste (de 33,6\% para 38,4\%). Nos estados, o percentual municipal só diminuiu em Alagoas, Ceará e Sergipe. Em 2007 ele oscilou do mínimo de 23,3\%, no Amapá, até o máximo de 67,1\%, no Maranhão. Em 2019 variou do mínimo de 35,6\%, no Amapá, até o máximo de $71,6 \%$, no Maranhão.

A presença privada, por sua vez, expandiu-se de $13,7 \%$, em 2006 , para $19,2 \%$, em 2019, com crescimento em todas as regiões: Norte (de 6,8\% para 9,4\%), Nordeste (de 12,1\% para $18,1 \%$ ), Sudeste (de $16,4 \%$ para $23,1 \%$ ), Sul (de 13,4\% para 18,2\%), Centro-Oeste (de 15,4\% para 18,7\%) e em 24 estados. Em 2006, sua participação variou do mínimo de 4,9\%, no Acre, até o máximo de 24,9\%, no Distrito Federal. Em 2019 oscilou do mínimo de 4,8\%, no Acre, até o máximo de $31,5 \%$, no Rio de Janeiro. Vale observar que no Ceará e no Rio de Janeiro as matrículas privadas já ultrapassam em 2019 as estaduais em valores percentuais e numéricos.

\begin{tabular}{|c|c|c|c|c|c|c|c|c|}
\hline & 2007 & & & & 2019 & & & \\
\hline & Total & Est \% & Mun. \% & Priv. (2006) \% & Total & Est. \% & Mun. \% & Priv. \% \\
\hline BRASIL & 53.804 .514 & 40,8 & 45,6 & 13,7 & 47.469 .439 & 32,2 & 48,5 & 19,2 \\
\hline NORTE & 5.203 .554 & 41,9 & 51,3 & 6,8 & 4.876 .872 & 35,3 & 55,3 & 9,4 \\
\hline Rondônia & 482.958 & 53,3 & 38,3 & 8,5 & 406.803 & 48,0 & 41,4 & 10,7 \\
\hline Acre & 248.629 & 61,5 & 33,7 & 4,9 & 261.717 & 57,3 & 38,0 & 4,8 \\
\hline Amazonas & 1.182 .322 & 42,4 & 50,6 & 7,1 & 1.154 .350 & 39,8 & 52,6 & 7,6 \\
\hline Roraima & 132.905 & 71,0 & 24,0 & 5,0 & 163.385 & 46,6 & 43,8 & 9,7 \\
\hline Pará & 2.505 .789 & 31,5 & 62,1 & 6,3 & 2.280 .114 & 24,9 & 64,7 & 10,3 \\
\hline Amapá & 225.492 & 67,0 & 23,3 & 9,7 & 217.511 & 54,6 & 35,6 & 9,8 \\
\hline Tocantins & 425.459 & 54,3 & 38,5 & 7,2 & 392.992 & 38,8 & 50,0 & 11,2 \\
\hline NORDESTE & 17.056 .326 & 30,1 & 57,8 & 12,1 & 13.837 .851 & 22,5 & 59,4 & 18,1 \\
\hline Maranhão & 2.327 .835 & 23,5 & 67,1 & 9,4 & 1.974 .447 & 16,4 & 71,6 & 12,0 \\
\hline Piauí & 1.077 .337 & 31,2 & 57,3 & 11,5 & 883.212 & 26,7 & 60,5 & 12,7 \\
\hline Ceará & 2.708 .471 & 23,8 & 61,7 & 14,5 & 2.149 .887 & 19,4 & 61,1 & 19,5 \\
\hline Rio Grande do Norte & 974.654 & 36,9 & 48,1 & 15,1 & 800.839 & 27,0 & 51,6 & 21,4 \\
\hline Paraíba & 1.187 .734 & 38,0 & 50,2 & 11,9 & 958.466 & 26,0 & 53,6 & 20,4 \\
\hline Pernambuco & 2.693 .286 & 34,3 & 49,0 & 16,7 & 2.214 .064 & 26,0 & 50,3 & 23,7 \\
\hline Alagoas & 1.005 .090 & 27,4 & 63,4 & 9,1 & 854.516 & 20,5 & 61,9 & 17,6 \\
\hline Sergipe & 623.239 & 37,7 & 50,8 & 11,5 & 538.724 & 27,9 & 49,8 & 22,4 \\
\hline Bahia & 4.458 .680 & 30,4 & 60,0 & 9,6 & 3.463 .696 & 22,3 & 61,1 & 16,6 \\
\hline SUDESTE & 20.822 .255 & 44,6 & 39,0 & 16,4 & 18.720 .693 & 34,8 & 42,1 & 23,1 \\
\hline Minas Gerais & 5.146 .000 & 49,6 & 37,5 & 13,0 & 4.320 .073 & 43,3 & 40,5 & 16,2 \\
\hline Espírito Santo & 932.585 & 33,5 & 52,6 & 14,0 & 868.148 & 28,5 & 59,1 & 12,4 \\
\hline Rio de Janeiro & 4.032 .311 & 33,4 & 45,3 & 21,2 & 3.533 .303 & 20,9 & 47,6 & 31,5 \\
\hline São Paulo & 10.711 .359 & 47,4 & 36,1 & 16,5 & 9.999 .169 & 36,6 & 39,4 & 24,0 \\
\hline SUL & 6.971 .482 & 49,0 & 37,7 & 13,4 & 6.403 .961 & 37,5 & 44,3 & 18,2 \\
\hline Paraná & 2.766 .592 & 48,9 & 37,8 & 13,2 & 2.547 .811 & 40,6 & 41,5 & 17,9 \\
\hline Santa Catarina & 1.593 .929 & 46,3 & 40,2 & 13,4 & 1.589 .802 & 33,1 & 49,7 & 17,2 \\
\hline Rio Grande do Sul & 2.610 .961 & 50,6 & 35,9 & 13,5 & 2.266 .348 & 37,0 & 43,6 & 19,4 \\
\hline
\end{tabular}




\begin{tabular}{lllllllll}
\hline CENTRO-OESTE & 3.750 .897 & 51,1 & 33,6 & 15,4 & 3.630 .062 & 43,0 & 38,4 & 18,7 \\
Mato Grosso do Sul & 694.659 & 43,9 & 44,0 & 12,1 & 674.648 & 34,1 & 52,3 & 13,6 \\
Mato Grosso & 869.049 & 50,5 & 40,7 & 8,7 & 870.427 & 44,5 & 42,7 & 12,7 \\
Goiás & 1.519 .708 & 44,1 & 39,4 & 16,5 & 1.436 .122 & 34,1 & 46,5 & 19,4 \\
Distrito Federal & 667.481 & 75,1 & & 24,9 & 648.865 & 69,8 & & 30,2 \\
\hline
\end{tabular}

Fontes: Censos Escolares de 2006, 2007 e 2019 (BRASIL. MEC. INEP, 2007; 2008a; 2020) e cálculos efetuados pelos autores.

A Tabela 10 mostra a classificação percentual crescente (da menor para a maior) da participação estadual no total de matrículas (sem as federais) na educação básica em cada Unidade da Federação em 2007 e 2019. Os seguintes aspectos merecem destaque: (a) as 12 menores redes estaduais se concentram no Nordeste, Pará, Espírito Santo e Rio de Janeiro, em 2007 e 2019; (b) quedas significativas da participação estadual de 2007 para 2019, o que, juntamente com o pequeno aumento da presença municipal, explica, pelo menos em parte, o crescimento privado no período.

Tabela 10 - Classificação percentual crescente da participação estadual no total de matrículas na educação básica no estado em 2007 e 2019

\begin{tabular}{|c|c|c|c|c|c|c|c|}
\hline \multirow[t]{2}{*}{2007} & \multicolumn{6}{|c|}{2019} & \multirow[b]{2}{*}{$\%$ part } \\
\hline & Total de mat. & Estadual & $\%$ part. & & Total de mat. & Estadual & \\
\hline 1. Maranhão & 2.327 .835 & 547.587 & 23,5 & 1. Maranhão & 1.974 .447 & 322.961 & 16,4 \\
\hline 2. Ceará & 2.708 .471 & 645.381 & 23,8 & 2. Ceará & 2.149 .887 & 417.009 & 19,4 \\
\hline 3. Alagoas & 1.005 .090 & 275.750 & 27,4 & 3. Alagoas & 854.516 & 174.932 & 20,5 \\
\hline 4. Bahia & 4.458 .680 & 1.356 .939 & 30,4 & 4. Rio de Janeiro & 3.533 .303 & 739.583 & 20,9 \\
\hline 5. Piauí & 1.077 .337 & 335.931 & 31,2 & 5. Bahia & 3.463 .696 & 771.344 & 22,3 \\
\hline 6. Pará & 2.505 .789 & 790.342 & 31,5 & 6. Pará & 2.280 .114 & 568.534 & 24,9 \\
\hline 7. Rio de Janeiro & 4.032 .311 & 1.348 .636 & 33,4 & 7. Paraíba & 958.466 & 249.241 & 26,0 \\
\hline 8. Espírito Santo & 932.585 & 312.061 & 33,5 & 8. Pernambuco & 2.214 .064 & 575.604 & 26,0 \\
\hline 9. Pernambuco & 2.693 .286 & 923.105 & 34,3 & 9. Piauí & 883.212 & 236.000 & 26,7 \\
\hline 10. R.G. Norte & 974.654 & 359.440 & 36,9 & 10. Rio G. Norte & 800.839 & 216.206 & 27,0 \\
\hline 11. Sergipe & 623.239 & 234.911 & 37,7 & 11. Sergipe & 538.724 & 150.087 & 27,9 \\
\hline 12. Paraíba & 1.187 .734 & 451.037 & 38,0 & 12. Espírito Santo & 868.148 & 247.721 & 28,5 \\
\hline 13. Amazonas & 1.182 .322 & 501.008 & 42,4 & 13. Santa Catarina & 1.589 .802 & 526.368 & 33,1 \\
\hline 14. M.G Sul & 694.659 & 304.864 & 43,9 & 14. M. G. Sul & 674.648 & 229.751 & 34,1 \\
\hline 15. Goiás & 1.519 .708 & 669.908 & 44,1 & 15. Goiás & 1.436 .122 & 489.327 & 34,1 \\
\hline 16. Santa Catarina & 1.593 .929 & 738.642 & 46,3 & 16. São Paulo & 9.999 .169 & 3.656 .265 & 36,6 \\
\hline 17. São Paulo & 10.711 .359 & 5.077 .518 & 47,4 & 17. R. G. Sul & 2.266 .348 & 838.776 & 37,0 \\
\hline 18. Paraná & 2.766 .592 & 1.353 .670 & 48,9 & 18. Tocantins & 392.992 & 152.370 & 38,8 \\
\hline 19. Minas Gerais & 5.146 .000 & 2.551 .433 & 49,6 & 19. Amazonas & 1.154 .350 & 459.735 & 39,8 \\
\hline 20. Mato Grosso & 869.049 & 439.271 & 50,5 & 20. Paraná & 2.547 .811 & 1.034 .030 & 40,6 \\
\hline 21. R. G. Sul & 2.610 .961 & 1.321 .994 & 50,6 & 21. Minas Gerais & 4.320 .073 & 1.870 .861 & 43,3 \\
\hline 22. Rondônia & 482.958 & 257.414 & 53,3 & 22. Mato Grosso & 870.427 & 387.397 & 44,5 \\
\hline 23. Tocantins & 425.459 & 230.864 & 54,3 & 23. Roraima & 163.385 & 76.073 & 46,6 \\
\hline 24. Acre & 248.629 & 152.799 & 61,5 & 24. Rondônia & 406.803 & 195.085 & 48,0 \\
\hline 25. Amapá & 225.492 & 151.115 & 67,0 & 25. Amapá & 217.511 & 118.791 & 54,6 \\
\hline 26. Roraima & 132.905 & 94.304 & 71,0 & 26. Acre & 261.717 & 149.833 & 57,3 \\
\hline 27. Dist. Fed. & 667.481 & 501.376 & 75,1 & 27. Dist.Fed. & 648.865 & 453.149 & 69,8 \\
\hline
\end{tabular}

Fontes: Censos Escolares de 2007 e 2019 (BRASIL. MEC. INEP, 2008a e 2020) e cálculos efetuados pelos autores. 
A Tabela 11 registra a classificação percentual decrescente (da maior para a menor) da participação municipal no total de matrículas (sem as federais) na educação básica em cada Unidade da Federação em 2007 e 2019. Os seguintes aspectos merecem destaque: (a) reduzido aumento da participação municipal de 2007 para 2019, embora essa participação tenha diminuído em Alagoas, Ceará e Sergipe; (b) as maiores participações se concentram no Nordeste, no Pará e Espírito Santo, o que pode ser explicado pela pequena e decrescente presença estadual.

Tabela 11 - Classificação percentual decrescente da participação municipal no total de matrículas na educação básica no estado em 2007 e 2019

\begin{tabular}{|c|c|c|c|c|c|c|c|}
\hline \multirow[t]{2}{*}{2007} & \multicolumn{6}{|c|}{2019} & \multirow[b]{2}{*}{$\%$ part } \\
\hline & Total de mat. & Municipal & $\%$ part. & & Total de mat. & Municipal & \\
\hline 1. Maranhão & 2.327 .835 & 1.561 .918 & 67,1 & 1. Maranhão & 1.974 .447 & 1.414 .160 & 71,6 \\
\hline 2. Alagoas & 1.005 .090 & 637.620 & 63,4 & 2. Pará & 2.280 .114 & 1.476 .215 & 64,7 \\
\hline 3. Pará & 2.505 .789 & 1.557 .011 & 62,1 & 3. Alagoas & 854.516 & 529.058 & 61,9 \\
\hline 4. Ceará & 2.708 .471 & 1.670 .593 & 61,7 & 4. Ceará & 2.149 .887 & 1.314 .605 & 61,1 \\
\hline 5. Bahia & 4.458 .680 & 2.673 .900 & 60,0 & 5. Bahia & 3.463 .696 & 2.117 .484 & 61,1 \\
\hline 6. Piauí & 1.077 .337 & 617.695 & 57,3 & 6. Piauí & 883.212 & 534.736 & 60,5 \\
\hline 7. Espírito Santo & 932.585 & 490.148 & 52,6 & 7. Espírito Santo & 868.148 & 513.069 & 59,1 \\
\hline 8. Sergipe & 623.239 & 316.419 & 50,8 & 8. Paraíba & 958.466 & 514.037 & 53,6 \\
\hline 9. Amazonas & 1.182 .322 & 597.841 & 50,6 & 9. Amazonas & 1.154 .350 & 606.694 & 52,6 \\
\hline 10. Paraíba & 1.187 .734 & 595.860 & 50,2 & 10. M. G. Sul & 674.648 & 353.037 & 52,3 \\
\hline 11. Pernambuco & 2.693 .286 & 1.319 .296 & 49,0 & 11. R. G. Norte & 800.839 & 413.309 & 51,6 \\
\hline 12. R. G. Norte & 974.654 & 468.490 & 48,1 & 12. Pernambuco & 2.214 .064 & 1.113 .913 & 50,3 \\
\hline 13. Rio de Janeiro & 4.032 .311 & 1.826 .840 & 45,3 & 13. Tocantins & 392.992 & 196.662 & 50,0 \\
\hline 14. M. G. Sul & 694.659 & 305.929 & 44,0 & 14. Sergipe & 538.724 & 268.231 & 49,8 \\
\hline 15. Mato Grosso & 869.049 & 353.778 & 40,7 & 15. Santa Catarina & 1.589 .802 & 790.410 & 49,7 \\
\hline 16. Santa Catarina & 1.593 .929 & 640.965 & 40,2 & 16. Rio de Janeiro & 3.533 .303 & 1.681 .988 & 47,6 \\
\hline 17. Goiás & 1.519 .708 & 599.175 & 39,4 & 17. Goiás & 1.436 .122 & 668.263 & 46,5 \\
\hline 18. Tocantins & 425.459 & 163.755 & 38,5 & 18. Roraima & 163.385 & 71.534 & 43,8 \\
\hline 19. Rondônia & 482.958 & 184.733 & 38,3 & 19. R. G.Sul & 2.266 .348 & 987.343 & 43,6 \\
\hline 20. Paraná & 2.766 .592 & 1.047 .053 & 37,8 & 20. Mato Grosso & 870.427 & 372.051 & 42,7 \\
\hline 21. Minas Gerais & 5.146 .000 & 1.928 .047 & 37,5 & 21. Paraná & 2.547 .811 & 1.058 .376 & 41,5 \\
\hline 22. São Paulo & 10.711 .359 & 3.868 .825 & 36,1 & 22. Rondônia & 406.803 & 168.215 & 41,4 \\
\hline 23. R. G. Sul & 2.610 .961 & 936.887 & 35,9 & 23. Minas Gerais & 4.320 .073 & 1.748 .301 & 40,5 \\
\hline 24. Acre & 248.629 & 83.762 & 33,7 & 24. São Paulo & 9.999 .169 & 3.939 .122 & 39,4 \\
\hline 25. Roraima & 132.905 & 31.936 & 24,0 & 25. Acre & 261.717 & 99.398 & 38,0 \\
\hline 26. Amapá & 225.492 & 52.535 & 23,3 & 26. Amapá & 217.511 & 77.410 & 35,6 \\
\hline
\end{tabular}

Fontes: Censos escolares de 2007 e 2019 (BRASIL. MEC. INEP, 2008a e 2020) e cálculos efetuados pelos autores.

A Tabela 12 registra a classificação percentual decrescente (da maior para a menor) da participação privada no total de matrículas (sem as federais) na educação básica em cada Unidade da Federação em 2006 e 2019. Aumentou em 24 estados, o que pode ser atribuído à queda estadual em quase todas as Unidades da Federação, e só diminuiu no Amapá, Piauí e Espírito Santo. 
Tabela 12 - Classificação percentual decrescente da participação privada no total de matrículas na educação básica no estado em 2006 e 2019

\begin{tabular}{|c|c|c|c|c|c|c|c|}
\hline \multirow[t]{2}{*}{2006} & Tot. de mat. & Privada & \multicolumn{2}{|r|}{2019} & Tot.de mat. & Privada & $\%$ part. \\
\hline & & & $\%$ part. & & & & \\
\hline 1. Dist. Fed. & 667.481 & 166.105 & 24,9 & 1. R. Janeiro & 3.533 .303 & 1.111 .732 & 31,5 \\
\hline 2. R. Janeiro & 4.032 .311 & 856.835 & 21,2 & 2. Dist. Fed. & 648.865 & 195.716 & 30,2 \\
\hline 3. Pernambuco & 2.693 .286 & 450.885 & 16,7 & 3. São Paulo & 9.999 .169 & 2.403 .782 & 24,0 \\
\hline 4. São Paulo & 10.711 .359 & 1.765 .016 & 16,5 & 4. Pernambuco & 2.214 .064 & 524.547 & 23,7 \\
\hline 5. Goiás & 1.519 .708 & 250.625 & 16,5 & 5. Sergipe & 538.724 & 120.406 & 22,4 \\
\hline 6. R. G. Norte & 974.654 & 146.724 & 15,1 & 6. R. G. Norte & 800.839 & 171.324 & 21,4 \\
\hline 7. Ceará & 2.708 .471 & 392.497 & 14,5 & 7. Paraíba & 958.466 & 195.188 & 20,4 \\
\hline 8. Espírito Santo & 932.585 & 130.376 & 14,0 & 8. Ceará & 2.149 .887 & 418.273 & 19,5 \\
\hline 9. R. G. Sul & 2.610 .961 & 352.080 & 13,5 & 9. R. G. Sul & 2.266 .348 & 440.229 & 19,4 \\
\hline 10. Santa Catarina & 1.593 .929 & 214.322 & 13,4 & 10. Goiás & 1.436 .122 & 278.532 & 19,4 \\
\hline 11. Paraná & 2.766 .592 & 365.869 & 13,2 & 11. Paraná & 2.547 .811 & 455.405 & 17,9 \\
\hline 12. Minas Gerais & 5.146 .000 & 666.520 & 13,0 & 12. Alagoas & 854.516 & 150.526 & 17,6 \\
\hline 13. M. G. Sul & 694.659 & 83.866 & 12,1 & 13. Santa Catarina & 1.589 .802 & 273.024 & 17,2 \\
\hline 14. Paraíba & 1.187.734 & 140.837 & 11,9 & 14. Bahia & 3.463 .696 & 574.868 & 16,6 \\
\hline 15. Piauí & 1.077 .337 & 123.711 & 11,5 & 15. Minas Gerais & 4.320 .073 & 700.911 & 16,2 \\
\hline 16. Sergipe & 623.239 & 71.909 & 11,5 & 16. M. G.Sul & 674.648 & 91.860 & 13,6 \\
\hline 17. Amapá & 225.492 & 21.842 & 9,7 & 17. Piauí & 883.212 & 112.476 & 12,7 \\
\hline 18. Bahia & 4.458 .680 & 427.841 & 9,6 & 18. Mato Grosso & 870.427 & 110.979 & 12,7 \\
\hline 19. Maranhão & 2.327 .835 & 218.330 & 9,4 & 19. Espírito Santo & 868.148 & 107.358 & 12,4 \\
\hline 20. Alagoas & 1.005 .090 & 91.720 & 9,1 & 20. Maranhão & 1.974 .447 & 237.326 & 12,0 \\
\hline 21. Mato Grosso & 869.049 & 76.000 & 8,7 & 21. Tocantins & 392.992 & 43.960 & 11,2 \\
\hline 22. Rondônia & 482.958 & 40.811 & 8,5 & 22. Rondônia & 406.803 & 43.503 & 10,7 \\
\hline 23. Tocantins & 425.459 & 30.840 & 7,2 & 23. Pará & 2.280 .114 & 235.365 & 10,3 \\
\hline 24. Amazonas & 1.182 .322 & 83.473 & 7,1 & 24. Amapá & 217.511 & 21.310 & 9,8 \\
\hline 25. Pará & 2.505 .789 & 158.436 & 6,3 & 25. Roraima & 163.385 & 15.778 & 9,7 \\
\hline 26. Roraima & 132.905 & 6.665 & 5,0 & 26. Amazonas & 1.154 .350 & 87.921 & 7,6 \\
\hline 27. Acre & 248.629 & 12.068 & 4,9 & 27. Acre & 261.717 & 12.486 & 4,8 \\
\hline
\end{tabular}

Fontes: Censos Escolares de 2006 e 2019 (BRASIL. MEC. INEP, 2007 e 2020) e cálculos efetuados pelos autores.

\section{Algumas conclusões}

Esses dados mostram que o Fundeb, apesar de trazer receitas adicionais para muitas prefeituras por meio da sua sistemática de repartição de parte dos impostos vinculados e/ou da complementação federal (esta bastante significativa para prefeituras do Nordeste e do Pará), não contribuiu para manter e desenvolver a educação básica pública, pelo menos no sentido de número de matrículas estaduais (6.620.267, ou $-30,2 \%)$ e municipais $(-1.503 .390$, ou $-6,1 \%$ ), que diminuíram de 2007 (primeiro ano do Fundeb) a 2019. Também o número de escolas estaduais diminuiu (-2.954, ou $-8,9 \%)$, assim como o de municipais (-24.136, ou $18,2 \%)$. O surpreendente na queda municipal é que milhares de prefeituras tiveram ganhos expressivos com o Fundeb, uma receita adicional aos $25 \%$ dos impostos, o que pode indicar que tais ganhos talvez não tenham sido aplicados devidamente em MDE, como é praxe nos governos e já apontado por muitos estudiosos e relatórios, como o senador João Calmon, no depoimento prestado à Comissão Parlamentar de Inquérito, que investigou a aplicação dos 
recursos da Emenda Calmon (BRASIL, 1989), e o da Comissão Parlamentar de Inquérito da Assembleia Legislativa do Estado de São Paulo (SÃO PAULO, 1999).

Tais dados expressam, a um só tempo, a necessidade de se ter mecanismos de transparência, tanto na recepção quanto no uso de recursos públicos, como também fortalecer os Conselhos de Acompanhamento e Controle Social dos Fundos.

Em vista das grandes diferenças na evolução das matrículas, as explicações geralmente apresentadas (queda da taxa de natalidade, correção do fluxo escolar) não nos parecem suficientes. Sem negar a importância delas, acreditamos que a redução deve ser atribuída principalmente a ações ou omissões deliberadas de governos estaduais e municipais. Tal encolhimento público, por sua vez, pode ter contribuído para a expansão do setor privado, tanto no número de matrículas $(+24,3 \%)$ de 2006 a 2019 , quanto no de escolas $(+16,6 \%)$.

Por isso, é preciso uma atitude de cautela em relação aos possíveis benefícios do Fundeb permanente, ou outro fundo com finalidade similar, caso venha a ser aprovado. Um aspecto essencial é destinar os recursos públicos exclusivamente para a educação básica pública. A Tabela 1 expressa que, em termos nacionais, somente as matrículas privadas cresceram, enquanto as estaduais e municipais declinaram. Todavia, apesar do decréscimo das públicas, estas ainda respondem pela vasta maioria das matrículas da educação básica no País, pois, das matrículas não-federais registradas em 2019, temos 38.334 .654 públicas (estaduais e municipais) e 9.134 .785 privadas.

Um novo Fundeb pode ser aprovado, mas devemos estar atentos, pois o Brasil é pródigo em leis boas que não são cumpridas, sobretudo quando beneficiam a maioria da população.

\section{Referências}

BRASIL. Constituição [de 1988] da República Federativa do Brasil. Diário Oficial da União [da] República Federativa do Brasil, Brasília, 5 out. 1988.

BRASIL. Congresso Nacional. Relatório da Comissão Parlamentar de Inquérito destinada a investigar a aplicação, pelo Ministério da Educação, dos recursos provenientes da Emenda Calmon. Diário do Congresso Nacional, Brasília, 29 jun. 1989. Seção I, suplemento.

BRASIL. Congresso Nacional. Lei No. 9.394, de 20/12/96. Estabelece as diretrizes e bases da educação nacional. Diário Oficial da União, Brasília, 1996. Disponível em: <http://www.planalto.gov.br>. Acesso em: 03 jul. 2019.

BRASIL. Congresso Nacional. Emenda Constitucional No. 53, de 19/12/06. Dá nova redação aos arts. $7^{\circ}, 23,30,206,208,211$ e 212 da Constituição Federal e ao art. 60 do Ato das Disposições Constitucionais Transitórias. Diário Oficial da União, Brasília, 2006. Disponível em: <http://www.planalto.gov.br>. Acesso em: 03 jan. 2007.

BRASIL. Congresso Nacional. Lei No. 11.494, de 20/6/07. Conversão da Medida Provisória No. 339, de 2006. Regulamenta o FUNDEB, altera a Lei No. 10.195, de 14/2/01, revoga dispositivos das Leis Nos. 9.424, de 24/12/96, 10.880, de 9/6/04, e 10.845, de 5/3/04, e dá outras providências. Diário Oficial da União, Brasília, 2007. Disponível em: <http://www.planalto.gov.br>. Acesso em: 02 jul. 2019.

BRASIL. Ministério da Educação. INEP. Censo da Educação Básica 2006. Brasília, DF: INEP, 2007. Disponível em: <http://www.inep.gov.br>. Acesso em: 15 jul. 2018. 
BRASIL. Ministério da Educação. INEP. Censo da Educação Básica 2007. Brasília, DF: INEP, 2008a. Disponível em: <http://www.inep.gov.br>. Acesso em: 15 jul. 2018.

BRASIL. Ministério da Educação. INEP. Sinopse Estatística da Educação Básica 2007. Brasília, DF: INEP, 2008b. Disponível em: <http://www.inep.gov.br>. Acesso em: 15 jul. 2018.

BRASIL. Ministério da Educação. INEP. Sinopse Estatística da Educação Básica 2008. Brasília, DF: INEP, 2009. Disponível em: <http://www.inep.gov.br>. Acesso em: 15 jul. 2018.

BRASIL. Ministério da Educação. INEP. Sinopse Estatística da Educação Básica 2019. Brasília, DF: INEP, 2020. Disponível em: <http://www.inep.gov.br>. Acesso em: 20 abr. 2020.

BUENO, Ederson Nunes; PERGHER, Calinca Jordânia. Analisando a trajetória dos fatores de ponderação estabelecidos no FUNDEB: 2007-2016. Fineduca. Revista de Financiamento da educação, Porto Alegre, v. 7, n. 6, p. 1-18, 2017.

CARVALHO, Marcelo Pagliosa. O financiamento da EJA no Brasil: repercussões iniciais do Fundeb. Revista Brasileira de Política e Administração da Educação, v. 30, n. 3, p. 635655, set./dez. 2014.

CNTE. Confederação Nacional dos Trabalhadores em Educação. Cinco razões para apoiar - Fundeb permanente e com mais recursos. Brasília, 2020. Disponível em: <http://www.cnte.org.br>. Acesso em: 30 mar. 2020.

DAVIES, Nicholas. Fundeb: a redenção da educação básica? Campinas: Autores Associados, 2008.

DAVIES, Nicholas. Levantamento bibliográfico sobre financiamento da educação no Brasil de 1988 a 2014. Educação em Revista, Marília, v. 15, n. 1, p. 91-162, jan./jun. 2014.

MARTINS, Paulo de Sena. A legislação do Fundeb. Cadernos de Pesquisa, São Paulo, v. 38, n. 134, p. 319-340, maio/ago. 2008.

MARTINS, Paulo de Sena. Fundeb, federalismo e regime de colaboração. Campinas: Autores Associados, 2011.

PERES, Alexandre José de Souza; SOUZA, Marcelo Lopes de; ALVES, Fabiana de Assis; RODRIGUES, Elenita Gonçalves. Efeito redistributivo intraestadual do Fundeb: uma análise a partir de variáveis financeiras, socioeconômicas e educacionais dos municípios. Brasília, DF: Instituto Nacional de Estudos e Pesquisas Educacionais Anísio Teixeira, 2015. (Série Documental. Textos para Discussão 39).

PINTO, José Marcelino de Rezende. A política recente de fundos para o financiamento da educação e seus efeitos no pacto federativo. Educação e Sociedade, Campinas, v. 28, n. 100, especial, p. 877-897, out. 2007.

PINTO, José Marcelino de Rezende. O Fundeb na perspectiva do custo aluno qualidade. Em Aberto, Brasília, v. 28, n. 93, p. 101-117, jan./jun. 2015.

PINTO, José Marcelino de Rezende; RIBEIRO, Josete Maria Cangussú; SONOBE, Aline Kazuko. Análise da evolução dos gastos por aluno em alguns estados brasileiros, suas respectivas capitais e sua relação com o Fundeb. Revista Brasileira de Política e Administração da Educação, v. 34, n. 2, p. 395-411, maio/ago. 2018. 
SALES, Luis Carlos; FRANÇA, Magna. Efeitos da Lei do Piso nos vencimentos de professores do Piauí e do Rio Grande do Norte no contexto da política de fundos. Revista Brasileira de Política e Administração da Educação, v. 34, n. 2, p. 461-478, maio/ago. 2018.

SÃO PAULO. Assembleia Legislativa. CPI da educação: uma ampla exposição de motivos. São Paulo, nov. 1999.

Nicholas Davies é professor titular aposentado da Faculdade de Educação da Universidade Federal Fluminense. Possui graduação em História pela Universidade Federal Fluminense (1983), mestrado em educação pela Universidade Federal Fluminense (1991) e doutorado em sociologia pela Universidade de São Paulo (1999). Tem experiência na área de Educação, com ênfase em política educacional, atuando principalmente nos seguintes temas: financiamento da educação, fundef, fundeb, orçamento da educação, público/privado, legislação educacional, livro didático e ensino de história.

ORCID: http://orcid.org/0000-0003-3826-0900

E-mail: nidavies1@hotmail.com

Alzira Batalha Alcântara é coordenadora e docente do PPGE da Unesa/ Docente associada da UERJ. Integra o Núcleo Interdisciplinar de Estudo do Espaço na Baixada Fluminense (NIESBF), atuando na linha de pesquisa "Política Pública, Trabalho, História e Educação" da UERJ.

ORCID: http://orcid.org/0000-0001-9597-282X

E-mail: alzirabatalha@hotmail.com 


\section{Editores do volume 10}

Márcia Aparecida Jacomini - Universidade Federal de São Paulo, Brasil

José Marcelino de Rezende Pinto - Universidade de São Paulo, Brasil

\section{Comitê Editorial}

Nalú Farenzena - Universidade Federal do Rio Grande do Sul, Brasil

Juca Gil - Universidade Federal do Rio Grande do Sul, Brasil

Theresa Adrião - Universidade Estadual de Campinas, Brasil

Ângelo Ricardo de Souza - Universidade Federal do Paraná, Brasil

\section{Conselho Editorial}

\section{Alejandro Morduchowicz}

Universidad Pedagógica, Provincia de Buenos Aires, Argentina

Andréa Barbosa Gouveia

Universidade Federal do Paraná, Brasil

Fernanda Saforcada

Universidade de Buenos Aires, Argentina

Jacques Velloso

Universidade de Brasília, Brasil

João Monlevade

Senado Federal, Brasil

Jorge Abrahão de Castro

Instituto de Pesquisa Econômica Aplicada / IPEA, Brasil

Lisete Regina Gomes Arelaro

Universidade de São Paulo, Brasil

Luis Carlos Sales

Universidade Federal do Piauí, Brasil

Luiz de Sousa Junior

Universidade Federal da Paraíba, Brasil

Luiz Fernandes Dourado

Universidade Federal de Goiás, Brasil

Magna França

Universidade Federal do Rio Grande do Norte, Brasil

Marcos Edgar Bassi

Universidade Federal de Santa Catarina, Brasil

Maria Angélica Pedra Minhoto

Universidade Federal de São Paulo, Brasil

Maria Beatriz Luce

Universidade Federal do Rio Grande do Sul, Brasil

Maria Dilnéia Espíndola Fernandes

Universidade Federal de Mato Grosso do Sul, Brasil

Nelson Cardoso do Amaral

Universidade Federal de Goiás, Brasil

Nicholas Davies

Universidade Federal Fluminense, Brasil

Robert E. Verhine

Universidade Federal da Bahia, Brasil

Romualdo Portela de Oliveira

Universidade de São Paulo, Brasil

Rosana Gemaque Rolim

Universidade Federal do Pará, Brasil

Rubens Barbosa de Camargo

Universidade de São Paulo, Brasil

Theresa Adrião

Universidade Estadual de Campinas, Brasil

Tristan McCowan

University of London, Reino Unido

Vera Jacob

Universidade Federal do Pará, Brasil

Vera Peroni

Universidade Federal do Rio Grande do Sul, Brasil

Vitor Henrique Paro

Universidade de São Paulo, Brasil

\section{Equipe editorial}

Apoio ao Comitê Editorial: Caio Cabral da Silva

Diagramação, Revisão de português e normalização: Edson Leonel de Oliveira

Revisão de inglês: Sabrina Ferreira

Fineduca - Revista de Financiamento da Educação

Associação Nacional de Pesquisa em

Financiamento da Educação

e-mail: revista.fineduca@gmail.com | site: http://seer.ufrgs.br/fineduca 